\title{
UM SUICIDA REDENTOR: uma análise retórica
}

\author{
Fernando Aparecido Ferreira ${ }^{1}$ \\ Maria Flávia Figueiredo ${ }^{2}$
}

\begin{abstract}
The will testament letter of the former President Getúlio Vargas, made public after his suicide in August 1954, had, on Brazilian politics, an impact that reversed the course of history: rescued (and greatly strengthened) the image of a worn leader and perpetuated his governance model for the following years. The writer of the letter shows a precise knowledge of his audience presumptions (the Brazilian people), predominantly Catholic by then, and believes in the ethos of "father of the poor" built for himself. Thus, he leaves a letter in which he converts, in a credible way, a religiously condemnable act (suicide) into a noble, redeemer one. In order to accomplish such semantic inversion, he makes use of allusions to the biblical text. Based on theoretical assumptions of Rhetoric, in the works of Aristotle (2005), Perelman and Olbrechts-Tyteca (2005), Meyer (2007), Reboul (2004) and Fiorin (2014) as well as the concept of intertextuality, worked for Piègay-Gros (1996) and Cavalcante (2011), this article seeks to scrutinize and understand the argumentative structure of the will testament letter of Vargas, seeking thus to identify the strategies that contributed to its rhetorical effectiveness.
\end{abstract}

Keywords: Rhetoric; Will testament letter; Getúlio Vargas; Intertextuality; Rhetorical ethos.

Resumo: A carta-testamento do ex-presidente Getúlio Vargas, levada a público após seu suicídio, em agosto de 1954, teve, sobre a política brasileira, um impacto que reverteu os rumos da história: resgatou (e fortaleceu sobremaneira) a imagem de um líder desgastado e perpetuou seu modelo de governo para os anos seguintes. $\mathrm{O}$ autor da carta demonstra um preciso conhecimento das presunções de seu auditório (o povo brasileiro), então majoritariamente católico, e confia no ethos de "pai dos pobres" que havia construído para si. Assim, deixa uma carta na qual converte, de forma verossímil, um ato condenável religiosamente (o suicídio) em um ato nobre, redentor. E, para realizar tal inversão semântica, lança mão de alusões ao texto bíblico. Fundamentado nos pressupostos teóricos da Retórica, presentes nas obras de Aristóteles (2005), Perelman e Olbrechts-Tyteca (2005), Meyer (2007), Reboul (2004) e Fiorin (2014), bem como no conceito de intertextualidade, trabalhado por Piègay-Gros (1996) e Cavalcante (2011), este artigo busca perscrutar e compreender a estrutura argumentativa da carta-testamento de Vargas, buscando, assim, identificar as estratégias que contribuíram para a sua eficácia retórica.

Palavras-chave: Retórica; Carta-testamento; Getúlio Vargas; Intertextualidade; Ethos retórico.

1 Universidade de Franca, fferreiradg@uol.com.br

2 Universidade de Franca, mariaflaviafigueiredo@yahoo.com.br 
Ao disparar um tiro de revólver contra o peito, na noite de 24 de agosto de 1954, tirando assim a sua própria vida, o então presidente do Brasil, Getúlio Vargas, cometeu um ato que até hoje é, a princípio, condenado em nossa sociedade, principalmente se levarmos em conta os dogmas das religiões. Essas, especialmente as cristãs, condenam os suicidas e a eles imputam "sanções". Conforme afirma Manhães (1990, p. 25) "as religiões cristãs não têm beneplácito para o suicida e os discriminam em seus rituais, negando-lhes os últimos sacramentos, a encomendação da alma e até a missa de sétimo dia". Segundo Cassorla (1986, p. 32), Santo Agostinho considerava o autoextermínio uma perversão e, para a Igreja, "o suicida é considerado um discípulo de Judas, um traidor da humanidade". Também para a sociedade o suicida é visto muitas vezes como um covarde, um fraco, alguém que, diante de uma crise, opta pela fuga e não pelo enfrentamento.

Para um chefe de uma nação, outrora inclusive um ditador, um ato contra a própria vida necessitou de uma justificativa, principalmente levando em conta a imagem de governante zeloso e "pai dos pobres" que Vargas havia construído para si, graças ao trabalho do Departamento de Imprensa e Propaganda de seu governo. Seu ato não poderia ser visto como um acovardamento, uma fuga ou como algo condenável para uma população então católica na sua grande maioria. Pensando no seu auditório ${ }^{3}$ - o povo brasileiro - Getúlio Vargas justificou-se na forma de uma carta datilografada (que passou a ser conhecida como sua "cartatestamento"). Nesse seu derradeiro discurso, valendo-se de uma notável retórica, Vargas faz de seu suicídio uma imolação e um ato de redenção. Em outras palavras, construiu um novo sentido para o suicídio, dando-lhe inclusive uma interpretação cristã, apresentando-se como um mártir. Pela palavra, Vargas faz do seu ato um sacrifício, oferecido às "aves de rapina" - seus "verdadeiros" assassinos, segundo leva a entender - para preservar o povo brasileiro, agindo como um pai protetor e amoroso, que dá a vida para os filhos. ${ }^{4}$

Sendo as opiniões sobre o suicídio sujeitas às crenças dos indivíduos e de uma sociedade, a retórica assume a tarefa de mobilizar a linguagem para transformar esse ato em algo razoável. No caso de Getúlio, esse intento foi tão bem sucedido a ponto de impedir um golpe militar que estava pronto para eclodir e acabou por fortalecer o ethos de "pai dos pobres", ao contrário de enfraquecê-lo. Segundo o historiador Boris Fausto, "Getúlio foi a figura política mais importante do Brasil no século XX, apesar de todas as suas contradições. Com a morte dele por razões políticas, com esse sacrifício, ele se converteu, perante as massas populares, num verdadeiro mito"s.

A eficácia retórica da carta-testamento também pode ser observada nas manchetes e notas de alguns jornais que noticiaram o suicídio. Publicações do Rio de Janeiro - então

3 O termo "auditório" é uma herança da retórica tradicional e refere-se ao "conjunto daqueles que o orador quer influenciar com sua argumentação.” (PERELMAN \& OLBRECHTS-TYTECA, 2005, p. 22, grifo dos autores).

4 Apesar do presente texto se dedicar à análise da carta datilografada, é importante ressaltar que o primeiro contato do povo brasileiro com o derradeiro discurso de Vargas ocorreu por meio da Rádio Nacional do Rio de Janeiro, meia hora após o suicídio (AGUIAR, 2004, p. 175). A carta só seria publicada nos jornais, em edições especiais, horas mais tarde. Segundo Baumworcel (2004, p. 22), "por intermédio do que era narrado, os ouvintes sentiram a 'alma sofrida de Vargas'. A sonoridade radiofônica trouxe simbolicamente Getúlio de volta. Era como se a palavra, ao ser dita, ganhasse corpo, se materializasse em imagens na mente do ouvinte". A prosódia advinda da locução da carta potencializou o sentido das palavras de Vargas e, consequentemente, ampliou seu efeito retórico. (Acerca da interrelação entre prosódia e persuasão, cf. Figueiredo (2006).)

5 FAUSTO, B. História do Brasil por Boris Fausto: República Populista (1945-1964). Disponível em: http:// www.youtube.com/watch?v=Jzgje3rR154\&hd=1. Acesso em: 10 maio 2014. 
capital do Brasil - como "Última hora" e "A noite", circularam com a ambígua manchete em letras garrafais: "Matou-se Vargas". A ordem sintática dessa frase permite duas classificações para o sujeito da oração: sujeito simples posposto ou sujeito indeterminado. Essas duas possibilidades propiciam duas leituras no nível semântico: Vargas se matou ou Vargas foi morto. Essa última leitura corrobora a vitimização do autor da carta-testamento - um mártir, não um suicida.

Tal leitura aparentemente também foi feita pela Igreja Católica na época, que, ao contrário de discriminar o presidente (pelo seu ato), conclamou sufrágios pela sua alma, conforme pode ser verificado em nota publicada no Jornal Correio do Povo, no dia seguinte ao suicídio:

\section{Missas em memória do presidente}

RIO, 24 (C.P.) - As autoridades religiosas acabam de recomendar que todas as missas de amanhã sejam realizadas em memória do sr. Getúlio Vargas.

(CORREIO DO POVO, 1954, p. 1)

Essa inversão dos valores de uma sociedade a partir do contato com um texto que a leva a aceitar um ato "condenável”, tomando-o por um outro ângulo, se faz possível por meio da retórica. Assim, como afirma Meyer (1998, p. 32), "a retórica surge quando aquilo que é pode, com toda a verossimilhança, ser diferente". Segundo esse autor, "a fronteira entre o louvor e a censura é totalmente retórica" (MEYER, 1998, p. 150). Talvez na ausência da elaborada argumentação da carta-testamento, o suicídio de Getúlio poderia ter sido veementemente reprovado, ou pelo menos essa reprovação poderia ter sido manifestada como um contra-argumento, minimizando assim a comoção e a revolta social que sucederam ao fato. ${ }^{6}$

A tese apresentada por Vargas, de que sua morte não foi ocasionada por ele, mas por outrem, foi aceita como verossímil pelo povo brasileiro. Essa aceitação se deu porque o presidente conhecia as presunções de seu auditório 7 . Sabia que a população o aceitava como um pai, um protetor ou, num viés religioso e místico, como uma figura messiânica. Evitando uma desmoralização caso renunciasse, Vargas opta pelo suicídio. Com uma argumentação adequada aos princípios e ideologias cristãs desse auditório, o ato condenável foi facilmente aceito pelo povo (isto é, tomado como verossímil) e transmutado em um ato nobre.

\section{Conforme explica Citelli:}

Verossímil é, pois, aquilo que se constitui em verdade a partir de sua própria lógica. Daí a necessidade, para se construir o "efeito de verdade", da existência de argumentos, provas, perorações, exórdios, conforme certas proposições já formuladas por Aristóteles na Arte Retórica. Persuadir não é apenas sinônimo de enganar, mas também o resultado de certa organização do discurso que o constitui como verdadeiro para o destinatário. (CITELLI, 2005, p. 15)

6 Na verdade, o efeito da carta foi tão devastador, que sedes de partidos e de jornais oposicionistas ao governo Vargas foram invadidas e atacadas pelo povo, impedindo assim manifestações de censura ou julgamentos negativos à atitude do presidente (AGUIAR, 2004, p. 175-176).

7 "As presunções têm função capital, pois constituem o que chamamos de 'verossímil', ou seja, o que todos admitem até prova em contrário. (...) O verossímil é a confiança presumida. (...) Em todo o caso, a presunção varia segundo os auditórios e as ideologias. Assim, para um conservador, o costume não precisa ser justificado, e sim a mudança. Para um liberal, o que não compete justificar é a liberdade, mas sim a coerção. Para um socialista, a igualdade é de direito, cumprindo justificar a desigualdade. $\mathrm{O}$ orador, portanto, precisa conhecer as presunções de seu auditório" (REBOUL, 2004, p. 165). 
Demonstrando um conhecimento do universo de expectativas e do posicionamento ideológico de seu auditório, com vistas a reforçar sua tese de redenção, Vargas lança mão de uma intertextualidade com as Sagradas Escrituras, utilizando esse recurso como um argumento de autoridade. Ademais, Vargas envolve seu leitor/ouvinte e nele desperta paixões, tecendo um texto no qual ele se iguala ao seu auditório (como um homem do povo) e, ao mesmo tempo, destaca-se como um líder, um reformador social, alguém capaz de conduzir sua gente a uma condição desejável.

Vejamos, então, como se constituiu a organização retórica da carta em análise.

\section{Um olhar sobre a estrutura retórica da carta-testamento ${ }^{8}$}

Para uma melhor compreensão da constituição retórica do texto meticulosamente tecido por Vargas, tomaremos como princípio de análise as provas de persuasão (trilogia retórica) propostas por Aristóteles. Para o filósofo grego, "as provas de persuasão fornecidas pelo discurso são de três espécies: umas residem no carácter moral do orador; outras, no modo como se dispõe o ouvinte; e outras, no próprio discurso, pelo que este demonstra ou parece demonstrar." Essas três instâncias referem-se, respectivamente, ao ethos, imagem de si transmitida pelo orador por meio do discurso, ao pathos, conjunto de emoções despertadas no auditório e ao $\log o s$, estrutura argumentativa do texto em si.

No papel de orador/autor da carta, Vargas, por um lado, apresenta um ethos de onipotente, de herói, de redentor da população e, por essa razão, de superior ao povo; por outro, apresenta um ethos de perseguido, de vítima, de injustiçado, portanto, de semelhante ao povo.

Por meio de seu discurso, no papel de orador/autor da carta, Vargas constrói diferentes imagens de si. Esses distintos ethé podem ser vislumbrados por meio de uma análise mais detalhada de alguns excertos da carta.

A ocorrência do ethos de herói, por exemplo, pode ser observada na seguinte frase: “Voltei ao governo nos braços do povo." Nela, encontramos a expressão "nos braços do povo" que confere ao orador o status de herói de uma população que o aclama e o carrega.

Se no trecho descrito acima é o povo que sustenta o retor pelo braço, no trecho a seguir é ele quem passa a proteger e amparar esse mesmo povo por meio de sua atitude. Dessa maneira, vê-se manifestado o ethos de redentor por meio das seguintes frases: "Nada mais vos posso dar a não ser meu sangue." e "Cada gota de meu sangue será uma chama imortal na vossa consciência." Esses dois excertos conferem ao orador o caráter de redentor pela "sacralidade" conferida à palavra sangue. Nesse contexto, essa palavra, que conota o viver e a própria existência, ganha o significado de salvação para aquele povo.

Esse ethos de redentor, que é garantido pelo orador por meio de seu "sacrifício redentor", ganha dimensão de onipotência nas seguintes frases: "Eu ofereço em holocausto a minha vida. Escolho este meio de estar sempre convosco." e "Meu sacrifício nos manterá unidos e meu nome será a vossa bandeira de luta. ” Dessa maneira, vislumbramos, nestes dois últimos exemplos, o ethos de onipotente.

Os ethé supracitados conferem ao orador uma condição de superioridade em relação à população a que ele se dirige. Por outro lado, os excertos a seguir evidenciam a manifestação de imagens de si que conferem ao orador traços de inferioridade em decorrência da conjuntura descrita na mesma carta. Primeiramente, verificamos a ocorrência de um ethos de perseguido, que pode ser observado nas seguintes frases: "Mais uma vez, as forças

8 Os excertos aqui utilizados manterão a ortografia e a pontuação originais, tal como foram datilografados na carta. 
que os interesses contra o povo coordenaram novamente, se desencadeiam sobre mim." e "Precisam sufocar a minha voz e impedir a minha ação, para que eu não continue a defender, como sempre defendi, o povo e principalmente os humildes."

A essa ideia de subordinação e "inferioridade" soma-se a ideia de vitimização e injustiça por parte do orador. No trecho "Não me acusam, me insultam; não me combatem, caluniam e não me dão o direito de defesa." verificamos a incidência do ethos de vítima por meio da oposição trazida na carga semântica dos verbos que se opõem: “acusar" X "insultar" e "combater" X "caluniar", e do ethos de injustiçado por meio da expressão "não me dão o direito de defesa".

Ainda no âmbito da subordinação, por meio das frases "Sigo o destino que me é imposto.", "Tive que renunciar." e "a ponto de sermos obrigados a ceder.", o orador apresenta o ethos de assujeitado, evidenciando sua falta de opção diante das circunstâncias que lhe foram impostas.

Podemos afirmar, portanto, que há uma oposição entre superioridade e subordinação no que tange à configuração ética do orador na carta-testamento. Por um lado, Vargas apresenta um ethos de onipotente, de herói, de redentor da população e, por essa razão, de superior ao povo; por outro, apresenta um ethos de perseguido, de vítima, de injustiçado, portanto, de semelhante ao povo.

Essa oposição, manifestada pelas distintas imagens transmitidas pelo orador, possibilita o afloramento de emoções também díspares no auditório, o que nos permite observar uma correlação entre as instâncias do ethos e do pathos no texto analisado.

Assim, com vistas à adesão do leitor/ouvinte, o texto de Vargas pode despertar no auditório ora os sentimentos de calma e amor, ora os sentimentos de indignação e compaixão. Os excertos analisados evidenciam que o orador parece ter logrado tal intento por meio das distintas imagens de si criadas em seu discurso. Se, por um lado, os ethé de herói, redentor e onipotente permitiram o afloramento de paixões como a calma e o amor, por outro, os ethé de perseguido, vítima e injustiçado favoreceram o surgimento de sentimentos como a indignação e a compaixão. Como enfatiza Plantin (2008, p. 117), "ethos e pathos representam, com efeito, duas modalidades de um mesmo trabalho com os afetos."

Já, quanto aos elementos retóricos oriundos do logos, ressalta-se o uso do lugar da quantidade e das figuras retóricas da repetição, da acumulação e da transposição. Exemplos dessas estratégias persuasivas podem ser verificados nos seguintes excertos:

\section{Lugar da quantidade.}

"Os lucros das empresas estrangeiras alcançavam até 500\% ao ano. Nas declarações de valores do que importávamos existiam fraudes constatadas de mais de cem milhões de dólares por ano."

\section{Figura retórica de repetição9 .}

Nos trechos abaixo, além da mera repetição de palavras, verifica-se a ocorrência do paralelismo ${ }^{10}$. Por meio dele, observamos a retomada de uma mesma estrutura oracional que passa a ser preenchida com vocábulos diferentes.

9 “A repetição é, portanto, um aumento da extensão de um dado texto com o emprego, várias vezes, do mesmo segmento textual (palavra, sintagma, oração, verso), para intensificar o sentido expresso.” (FIORIN, 2014, p. 116)

10 Paralelismo ou isócolo é uma figura de repetição estrutural. (cf. FIORIN, 2014, p. 138) 


\section{Conexão Letras}

"Não me acusam, me insultam;

não me combatem, caluniam e

não me dão o direito de defesa."

"Não querem que o trabalhador seja livre.

Não querem que o povo seja independente. '

"Quando vos humilharem sentireis minha alma sofrendo a vosso lado.

Quando a fome bater a vossa porta, sentireis em vosso peito a energia para a luta por vós e vossos filhos.

Quando vos vilipendiarem, sentireis no meu pensamento a força para a reação.

“Ao ódio respondo com o perdão.

E aos que pensam que me derrotaram respondo com a minha vitória."

"Lutei contra a espoliação do Brasil.

Lutei contra a espoliação do povo.

Tenho lutado de peito aberto."

3. Figura retórica de acumulação.

a) antítese ${ }^{11}$ :

"E aos que pensam que me derrotaram respondo com a minha vitória."

"Era escravo do meu povo e hoje me liberto para a vida eterna."

"Vos dei a minha vida. Agora ofereço a minha morte.

b) gradação ${ }^{12}$ :

"Tenho lutado mês a mês, dia a dia, hora a hora"

c) enumeração ${ }^{13}$ :

"O ódio as infâmias, a calunia, não abateram meu animo."

4. Figura retórica de transposição ${ }^{14}$.

"Mais uma vez, as forças que os interesses contra o povo coordenaram novamente, se desencadeam sobre mim."

"e mal começa esta a funcionar"

"Contra a justiça da revisão do salario minimo se desencadearam os odios."

"Nada mais vos posso dar"

11 De acordo com FIORIN (2014, p. 152), “a antítese é um acúmulo de significados, porque se explicitam as oposições implícitas na construção dos sentidos. Isso para intensificar o que se diz, mostrando contradições e contrariedade presentes no objeto de que se fala."

12 Por meio de palavras ou de um grupo de palavras de significado relacionado, a figura da gradação ou clímax permite a intensificação crescente de um enunciado. "A gradação é, pois, uma sequência de significados dispostos numa ordem ascendente, em que o posterior diz um pouco mais do que o anterior.” (FIORIN, 2014, p. 147)

13 Por meio dessa figura, enumeram-se os diversos aspectos de um objeto ou de um evento a fim de se intensificar o sentido. (cf. FIORIN, 2014, p. 141)

14 Nas figuras de transposição (anástrofe, hipérbato ou sínquise), inverte-se a ordem habitual das palavras. Dessa forma, um ou mais termos são alçados a uma posição de proeminência, o que produz uma intensificação de seu sentido. (cf. FIORIN, 2014, p. 171) 
"eu ofereço em holocausto a minha vida."

"Ao ódio respondo com o perdão."

Além dos recursos supracitados, encontramos, na carta-testamento, uma estratégia retórica, também atrelada ao logos, que nos pareceu de grande relevância: o uso da intertextualidade como argumento de autoridade. Dada sua relevância no texto em estudo, os parágrafos subsequentes serão dedicados ao entendimento desse processo.

\section{A intertextualidade como argumento de autoridade}

Os dados emanados da carta-testamento permitem-nos observar, com certa clareza, as marcas de intertextualidade nela presentes. Essa relação com outros textos se manifesta na carta por meio de uma evocação às Sagradas Escrituras e à interpretação cristã do sacrifício redentor. Nesse sentido, podemos considerar que a intertextualidade detectada tem um cunho retórico junto àquele auditório específico, exercendo a função de argumento de autoridade.

A intertextualidade, “que teve sua origem na Teoria Literária durante a década de 60, é hoje entendida pela Linguística Textual como a relação que um texto estabelece com outros textos anteriormente produzidos." (FIGUEIREDO e CARMELINO, 2010, p. 71).

Mozdzenski (2013) descreve a classificação feita por com Piègay-Gros (1996), a qual é de grande auxílio para o entendimento do fenômeno da intertextualidade. Nas palavras do autor:

Piègay-Gros (1996) divide as relações intertextuais em dois tipos: relações de copresença entre dois ou mais textos e relações de derivação de um ou mais textos a partir de um texto-matriz. No primeiro grupo, a autora elenca a citação (o texto é inserido expressamente em outro); a referência (similar à citação, mas sem transcrição literal do texto-fonte); a alusão (o texto-matriz é retomado de forma sutil, por indicações que o leitor deve perceber); e o plágio (a citação não vem marcada). Já no segundo grupo, encontram-se a paródia (a estrutura e o assunto do texto são retomados em outras situações com efeitos de carnavalização e de ludismo); o travestismo burlesco (reescritura de um estilo a partir de uma obra cujo conteúdo é conservado); e o pastiche (imitação de um estilo com utilização da mesma forma do texto imitado). (MOZDZENSKI, 2013, p. 180-181)

Partindo dessa classificação, podemos verificar, no corpus, a intertextualidade por copresença em forma de alusão. A esse respeito, Cavalcante e Brito (2011, p. 273) discorrem que a alusão é uma espécie de referenciação indireta, que se constrói por meio do "apelo a algo que se espera familiar para os interlocutores", recorrendo, portanto, à memória do coenunciador.

Vários trechos da carta-testamento dialogam, em forma de alusão, com diferentes livros que compõem a bíblia, como demonstram os excertos listados a seguir ${ }^{15}$ :

1. "Escolho este meio para estar sempre convosco" (CT)

E eis que eu estou convosco todos os dias, até a consumação dos séculos! (Mateus 28:20)

15

Em itálico, encontram-se os excertos da carta-testamento (CT), seguidos, em negrito, dos trechos bíblicos a que aludem, com seus respectivos livros. 
Esses trechos revelam a crença na possibilidade de onipresença por parte de Vargas após a sua morte, assim como a de Jesus, após sua ressurreição. Nesse sentido, Vargas se apresenta amalgamado a seu povo, numa busca incessante de construir, retoricamente, a ideia de identificação com a população. Ao fazê-lo, tece um pacto com o auditório, o qual, na verdade, só pode se consolidar em termos espirituais. Daí nossa afirmação a respeito da crença na possibilidade de onipresença.

O trecho do evangelho de Lucas aqui citado foi extraído de um episódio ${ }^{16}$ em que Jesus, morto e ressuscitado, buscava consolidar as bases para o povo cristão. Assim, após pedir aos seus discípulos que seguissem seus ensinamentos e fizessem mais discípulos por toda a terra, prometeu estar sempre com eles até o fim dos tempos, garantindo, assim, a sua onipresença.

Nesse trecho da carta-testamento, fica patente que o suicídio é utilizado como uma possibilidade de permanência da vida e não como um atentado contra ela. Diante da pressão de seus "algozes" que queriam distanciá-lo de seu povo, Vargas encontra "este meio" de continuar sua liderança, desta vez transferida para um plano espiritual.

\section{2. "Quando vos humilhares sentireis minha alma sofrendo a vosso lado" (CT) \\ Porque Iahweh vosso Deus marcha convosco, lutando a vosso favor contra os vossos inimigos, para salvar-vos!"” (Deuteronômio 20:4)}

Permanece, nesse trecho, a crença da onipresença de Vargas junto a seu auditório. Assim como no texto bíblico, em que Deus marcha junto com seu povo, o orador da carta passa ao auditório a sensação de não-abandono. Dessa maneira, deixar a vida não significa desamparar o seu povo, mas sim a possibilidade de protegê-lo plenamente.

3. "Cada gota de meu sangue será uma chama imortal na vossa consciência e manterá a vibração sagrada para a resistência” (CT)

E disse-lhes: "Isto é o meu sangue, o sangue da Aliança, que é derramado em favor de muitos". (Marcos 14:24)

E, depois de comer, fez o mesmo com o cálice, dizendo: "Este cálice é a Nova Aliança em meu sangue, que é derramado em favor de vós". (Lucas 22:20)

O sangue aparece na carta-testamento como uma fonte de energia ("chama imortal”). Por meio dele, Vargas incita seu auditório à conscientização. Seu sacrifício ficará latejando na consciência do povo e, por conseguinte, manterá viva a sua memória, aqui metaforizada como um coração que continuará a pulsar ( "vibração sagrada"). Em outras palavras, sua morte será um combustível para a continuidade de seu projeto.

Tanto a carta-testamento como os trechos bíblicos selecionados reforçam a ideia de um pacto do líder com seus seguidores. Em ambos, o sangue é usado como símbolo para esse pacto. Dessa forma, assim como Jesus usa seu sangue para selar uma aliança com seu povo, Vargas busca fazer o mesmo em relação à população brasileira, o que o coloca numa posição messiânica.

16 "A aparição de Jesus na Galiléia e a missão universal - ${ }^{16}$ Os onze discípulos caminharam para a Galiéia, à montanha que Jesus lhes determinara. ${ }^{17}$ Ao vê-lo, prostraram-se diante dele. Alguns, porém, duvidaram. ${ }^{18} \mathrm{~J}$ esus, aproximando-se deles, falou: 'Toda a autoridade sobre o céu e sobre a terra me foi entregue. ${ }^{19}$ Ide, portanto, e fazei que todas as nações se tornem discípulos, batizando-as em nome do Pai, do Filho e do Espírito Santo ${ }^{20} \mathrm{e}$ ensinando-as a observar tudo quanto vos ordenei. E eis que eu estou convosco todos os dias, até a consumação dos séculos!'” (Mateus 28,16-20) 
4. "E aos que pensam que me derrotaram respondo com a minha vitória" (CT)

Então cumprir-se-á a palavra da Escritura: A morte foi absorvida na vitória. (1 Coríntios 15:54)

Como consequência do excerto anterior, a morte de Vargas foi construída retoricamente como sua vitória e não sua derrota, já que ele continuará governando por meio do pacto assumido. Mas tudo isso só se faz possível em função de uma crença compartilhada: a ideia de vida eterna.

5. "Era escravo do povo e hoje me liberto para a vida eterna" (CT)

Esta é a promessa que ele mesmo vos fez: a vida eterna. (1 João 2:25)

A fim de que todo aquele que crer tenha nele vida eterna. (João 3:15)

Em verdade, em verdade, vos digo: aquele que crê tem a vida eterna. (João 6:47)

E irão estes para o castigo eterno, enquanto os justos irão para a vida eterna. (Mateus 25:46)

O conceito de "vida eterna", amplamente difundido na bíblia, é retomado por Vargas. E não apenas isso, ele se coloca entre os justos, como merecedor de tal recompensa, dissimulando, assim, seu ato condenável.

Outra ideia presente nesse excerto da carta é a da libertação após um período de escravidão. Isso nos permite inferir que ele se coloca como escravo de um povo que era também escravo e, assim como ele se libertará por meio da morte, esse povo também poderá se libertar por meio de seu ato "redentor".

6. “Ao ódio respondo com o perdão" (CT)

Eu, porém, vos digo: não resistais ao homem mau; antes, àquele que te fere na face direita oferece-lhe também a esquerda. (Mateus 5:39)

Portanto, deveis ser perfeitos como o vosso Pai celeste é perfeito (Mateus 5:48)

Eu, porém, vos digo, a vós que me escutais: Amai os vossos inimigos, fazei bem aos que vos odeiam, bendizei os que vos amaldiçoam, orai por aqueles que o difamam. (Lucas, 6:27-28)

Jesus dizia: "Pai, perdoa-lhes: não sabem o que fazem". (Lucas 23:34)

Sede bondosos e compassivos uns com os outros, perdoando-vos mutuamente, como Deus em Cristo vos perdoou. (Efésios 4:32)

Nesse trecho da carta-testamento, o orador apresenta um ethos de benevolente, condizente com a postura esperada de um cristão (ou de alguém que quer se igualar a Cristo), ou seja, aquele que, ao ser insultado, oferece a outra face. Na ótica cristã, ao perdoar seus inimigos, Vargas se coloca numa posição de superioridade e perfeição do ser.

Aparentemente, o propósito comunicacional dessa declaração é fazer mais uma alusão ao universo cristão e seus preceitos, aqui empregados para dissimular a vingança que Vargas arquiteta com seu suicídio. Na verdade, ao contrário de perdoar, com sua morte, Vargas incita o seu povo a se voltar contra "as aves de rapina" (como ele se refere aos seus algozes em outro trecho da carta).

7. "Mas esse povo de quem fui escravo, não mais será escravo de ninguém” (CT)

É para a liberdade que Cristo nos libertou. Permanecei firmes, portanto, e não vos deixeis prender de novo ao jugo da escravidão. (Gálatas 5:1) 
Esse trecho da carta-testamento apresenta uma relação intertextual muito evidente com o texto paulino (a carta aos Gálatas). Tanto é que se trocarmos o nome de Cristo pelo de Vargas, no excerto bíblico, o sentido abstraído do trecho da carta-testamento aqui em análise se manterá inteiramente. Vejamos: É para a liberdade que eu, Vargas, vos libertei. Permanecei firmes, portanto, e não vos deixeis prender de novo ao jugo da escravidão.

8. "Meu sacrifício ficará para sempre em sua alma e meu sangue será o preço do seu resgate" (CT)

E é pelo sangue deste que temos a redenção, a remissão dos pecados, segundo a riqueza da sua graça (Efésios 1:7)

Pois há um só Deus, e um só mediador entre Deus e os homens, um homem, Cristo Jesus, que se deu em resgate por todos. (1 Timóteo 2:5-6)

Desse modo, o Filho do Homem não veio para ser servido, mas para servir e dar a sua vida em resgate por muitos. (Mateus 20:28)

Por fim, o último trecho a ser analisado é aquele que traz o maior número de elementos lexicais relativos ao sacrifício redentor. Por essa razão, cremos que esse trecho sela a relação intertextual entre a carta de Vargas e o texto bíblico. Os temos utilizados foram: "sacrifício", "alma", "sangue", "resgate". O uso desses quatro termos em sequência evidencia a crença de Vargas de que seu auditório, de fato, compartilhava de seu universo místico-cristão.

A carga semântica da frase como um todo já foi discutida nos excertos precedentes, porém, vale ressaltar que a correlação entre os termos "sacrifício" e "resgate" só se manifesta com clareza nesse trecho da carta. E, essa mesma correlação é amplamente difundida no texto bíblico, dada a centralidade do sacrifício redentor de Cristo com vistas à salvação de toda a humanidade. Por esse motivo, elencamos, não apenas um, mas, três excertos do Novo Testamento que ressaltam a papel do "resgate" de todo um povo por intermédio da morte de um único indivíduo.

A análise dos oito excertos da carta-testamento nos permite concluir que, por meio da intertextualidade em forma de alusão, Vargas busca se equiparar a Jesus. Ao fazê-lo, isto é, ao se igualar ao "Messias" (que também deu a vida pelo seu povo), ele se impõe como uma pessoa de prestígio, detentora de uma palavra de honra; palavra está compactuada com um auditório que tem Cristo e a bíblia como referências inquestionáveis. É nesse sentido que a intertextualidade da carta-testamento com as sagradas escrituras se apresenta como um argumento de autoridade, já que este, segundo Perelman e OlbrechtsTyteca (2005, p. 348), se sustenta em "atos ou juízos de uma pessoa ou de um grupo de pessoas como meio de prova a favor de uma tese". E, segundo os autores, "quanto mais importante é a autoridade, mais indiscutíveis parecem suas palavras. [Além de que,] no limite, a autoridade divina sobrepuja todos os obstáculos que a razão poderia opor-lhe" (2005, p. 351, grifos nossos).

\section{Considerações finais}

Em recente entrevista ${ }^{17}$, divulgando o lançamento do último volume da sua elogiada biografia de Vargas, o jornalista Lira Neto afirma que até hoje o ex-presidente segue ge-

17 LIRA NETO, J. Entrevista concedida ao programa Metrópolis (TV Cultura). Disponível em: $<$ http://tvuol.uol.com.br/video/o-suicidio-de-getulio-adiou-o-golpe-militar-para-1964-diz-escritor-04028C9B3460CC915326>. Acesso em: 10 out. 2014. 
rando reações passionais. Não é exagero dizer que sua carta-testamento é uma peça fundamental nesse contínuo incitar do pathos que provém de sua trajetória enquanto homem público. Tal como profetizado em seu discurso final, de fato pode-se dizer que Vargas tornou-se uma "chama imortal" na consciência do povo brasileiro.

A estrutura argumentativa da carta revela o diálogo intertextual entre o sacrifício redentor de Vargas, retoricamente construído em sua carta-testamento, e o de Jesus Cristo, tal como concebe a tradição cristã fundamentada nos textos sagrados. Esse diálogo foi o responsável pela constituição da intertextualidade como argumento de autoridade no corpus analisado.

No que se refere à imagem de si passada pelo orador, a par dos ethé elencados e dos respectivos pathé por eles despertados, pudemos verificar que, por meio da alusão à trajetória de Cristo, Vargas reforça o ethos de Messias, o qual veio sendo construído ao longo de seus governos. Na verdade, sua morte trágica se apresentou como o arremate perfeito para essa construção ética.

Portanto, sua carta-testamento, não é apenas uma elaborada justificativa para que seu suicídio fosse visto como um ato heroico e honrado e não como uma atitude covarde, de desespero, é também, na sua intertextualidade com os textos bíblicos, na sua alusão à paixão de Cristo e na evocação de uma simbologia mística compartilhada com seu auditório, uma elaborada construção retórica que não só inverte as noções negativas associadas a um ato condenável, como também converte o protagonista desse ato num homem "santo"18.

\section{Referências}

AGUIAR, R. C. Vitória na derrota: a morte de Getúlio Vargas. Rio de Janeiro: Casa da Palavra, 2004.

ARISTÓTELES. Retórica. Tradução e notas de Manuel Alexandre Júnior, Paulo Farmhouse Alberto e Abel do Nascimento Pena. 2. ed. rev. Lisboa: Imprensa Nacional Casa da Moeda, 2005. (Coleção Biblioteca Clássica)

BAUMWORCEL, A. 1954: um retrato do rádio na época de Vargas. In: BAUM, A. (Org.): Vargas, agosto de 54: a história contada pelas ondas do rádio. Rio de Janeiro: Garamond, 2004.

BÍBLIA DE JERUSALÉM. Disponível em: <http://tifsa.com.br/a-biblia-de-jerusalemcompleta/>. Acesso em: 30 set. 2014.

CASSORLA, R. M. S. O que é suicídio. 2. ed. São Paulo: Brasiliense, 1986.

CAVALCANTE, M. M.; BRITO, M. A. P. Intertextualidades, heterogeneidades e referenciação. Linha d'água, v. 24, p. 260-276, 2011.

CITELLI, A. Linguagem e persuasão. 16. ed. São Paulo: Ática, 2005. (Série Princípios, 17)

CORREIO DO POVO. Porto Alegre, quarta-feira, 25 ago. 1954.

FAUSTO, B. História do Brasil por Boris Fausto: República Populista (1945-1964).

Disponível em: http://www.youtube.com/watch?v=Jzgje3rR154\&hd=1. Acesso em: 10 maio 2014.

18 Após seu suicídio, impressos com reprodução do texto da sua carta-testamento, acompanhado de sua foto, foram propagados tal como uma oração (um "santinho"), com o título "Carta de Vargas aos humildes" e com a seguinte recomendação no rodapé: "Coloque esta carta num quadro". 


\section{Conexão Letras}

FIGUEIREDO, M. F. (publicado originalmente como BOLLELA, M. F. F. P.) $A$ prosódia como instrumento de persuasão. In: LOUZADA, M. S. O.; NASCIMENTO, E. M. F. S.; OLIVEIRA, M. R. M.. (Orgs.). Processos enunciativos em diferentes linguagens. Franca: UNIFRAN, 2006. p. 113-128. (Coleção Mestrado, 1) FIGUEIREDO, M. F.; CARMELINO, A. C. A multiplicidade de gêneros presente nos evangelhos: um caso de intertextualidade. In: II SIMELP, 2010, Évora, Portugal. Língua Portuguesa: ultrapassar fronteiras, juntar culturas. Évora, Portugal: Editora da Universidade de Évora, 2010. p. 65-86.

FIORIN, J. L. Figuras de retórica. São Paulo: Contexto, 2014.

LIRA NETO, J. Entrevista concedida ao programa Metrópolis (TV Cultura). Disponível em: <http://tvuol.uol.com.br/video/o-suicidio-de-getulio-adiou-o-golpe-militar-para1964-diz-escritor-04028C9B3460CC915326>. Acesso em: 10 out. 2014.

MANHÃES, M. P. O enigma do suicídio. Rio de Janeiro: Imago, 1990.

MEYER, M. Questões de retórica: linguagem, razão e sedução. Tradução António Hall. Lisboa: Edições 70, 2007.

MOZDZENSKI, Leonardo. Intertextualidade verbo-visual: como os textos multissemióticos dialogam? Bakhtiniana, São Paulo, n. 8., v. 2, p. 177-201, Jul./Dez. 2013.

PERELMAN, C.; OLBRECHTS-TYTECA L. Tratado da argumentação: a nova retórica. Tradução Maria Ermentina Galvão G. Pereira. 2. ed. São Paulo: Martins Fontes, 2005.

PIÈGAY-GROS, N. Introduction à l'intertextualité. Paris: Dunod, 1996.

PLANTIN, C. A argumentação. Tradução Marcos Marcionilo. São Paulo: Parábola Editorial: 2008.

REBOUL, O. Introdução à retórica. Tradução Ivone Castilho Benedetti. 2. ed. São Paulo: Martins Fontes, 2004. 